\title{
Nutrition Education Influences Child Feeding Knowledge Attitudes and Practices of Caregivers in Uganda
}

\author{
Josephine Nabugoomu ${ }^{1}{ }^{*}$, Agnes Namutebi ${ }^{1}$, Archileo N. Kaaya ${ }^{1}$, George Nasinyama ${ }^{2}$ \\ ${ }^{1}$ Department of Food Technology and Nutrition, Makerere University, Kampala, Uganda \\ ${ }^{2}$ Department of Biosecurity, Ecosystems and Veterinary Public Health, Makerere University, Kampala, Uganda
}

Email address:

jnabugoomu@yahoo.com (J. Nabugoomu), asnamutebi@caes.mak.ac.ug (A. Namutebi), kaaya.archileo48@gmail.com (A. N. Kaaya), nasinyama@covab.mak.ac.ug (G. Nasinyama)

\section{To cite this article:}

Josephine Nabugoomu, Agnes Namutebi, Archileo N. Kaaya, George Nasinyama. Nutrition Education Influences Child Feeding Knowledge Attitudes and Practices of Caregivers in Uganda. American Journal of Health Research. Vol. 3, No. 2, 2015, pp. 82-90.

doi: $10.11648 /$ j.ajhr.20150302.15

\begin{abstract}
A Cross-sectional sample of households that were involved in farming of orange-fleshed sweet potato (OFSP) and had 2-6 year old children were purposively selected from four divisions of Kampala Capital City Authority (Kawempe, Rubaga, Makindye and Nakawa) to participate in a controlled, cohort intervention. Respondents in Kawempe division had received training in production of OFSP and nutrition education; in Rubaga division respondents had only training in production of OFSP; in Nakawa division they only had nutrition education while in Makindye division the respondents did not training in nutrition education and production of OFSP and thus served as the control. A total of 457 households were involved in the study and a coded questionnaire was used to collect data on caregiver's knowledge, attitudes and practices of child nutrition after the 12 month intervention. Chi-square tests were used to test for significant relationships ( $\mathrm{p} \leq 0.05)$ amongst variables of interest. Results of the study show that majority of the children (2-6 years) take their meals from that of the family. At least $20 \%$ of the respondents serve lunch and dinner separately for the child with no significant differences among the divisions. Thus any major nutritional interventions should target the caregivers' knowledge, attitudes and practices of child feeding and the first meal the child takes. On preparation of meat, $71 \%$ of the respondents who received nutrition education gave correct advice compared to $28 \%$ who did not receive the intervention. With regard to Maize porridge and beans preparation, significant differences could not be attributed to the intervention. However, $40 \%$ of the respondents in Nakawa and Makindye gave advice that was not helpful and so could not be adequately followed in the correct preparation of maize porridge and beans for the children. Preparation of kitoobero, a highly nutritious complementary dish for weaning children, was taught during the nutrition education sessions. Significantly more respondents who received nutrition education identified at least two combinations of foods used for kitoobero $(65 \%)$ compared to about $5 \%$ of those who did not receive the intervention. The study found that majority of the respondents, $65 \%$ and $80 \%$ respectively in Kawempe and Rubaga compared to over $85 \%$ in Nakawa and Makindye had not prepared kitoobero seven days prior to the study. The results show that nutrition education significantly impacts on knowledge of meal preparation for weaning children, attitudes, and practices of child feeding. It is recommended that nutrition education as a strategy of improving child feeding knowledge and practices should be taken up by the public health sector so as to boost the fight against malnutrition which is a major problem in Uganda.
\end{abstract}

Keywords: Nutrition Education, Child Feeding Practices, Caregivers, Malnutrition

\section{Introduction}

Children require adequate nutrition for their physical and mental growth. Poor and inadequate nutrition in infancy and childhood leads to malnutrition with its effects such as morbidity and mortality and delayed mental and motor development. ${ }^{(1-3)}$ These effects may in the long term be linked to impairments in intellectual capacity, work capacity and reproductive outcomes. ${ }^{(4)}$

After the age of 6 months, breast milk alone is no longer sufficient to provide all the nutritional requirements of an infant and so breast milk has to be complemented with other foods and liquids. ${ }^{(5,6)}$ However, there may be inconsistencies in the foods for making complementary feeds, method of preparation, amount, frequency, and diversity of 
complementary feeds given to children at different ages. ${ }^{(2,7,8)}$ The WHO therefore developed guidelines for complementary feeding of infants and young children using locally available foods. Theses guideline include: maintaining breastfeeding until age of 2 years and beyond; practicing responsive feeding; using clean hands and utensils to prepare, cook, serve, and store complementary feeds; combining several foods and varying them in terms of taste, color, and texture; feeding or assisting children to feed and making meal time pleasant; assuring that the number of times the child is fed with complementary feeds in a day provides the child with adequate e energy density of balanced complementary feeds. ${ }^{(1)}$

Inadequate and inappropriate complementary foods, poor nutrition knowledge of mothers/child caretakers, and poor caregivers' practices have been linked to child malnutrition. ${ }^{(9-}$ 13) In Uganda, due to a number of reasons, complementary foods are not introduced on time for all children leading to malnutrition. ${ }^{(14-16)}$. The Uganda Demographic Health Survey (2011) reported that $33 \%$ of the children in Uganda were stunted, while $5 \%$ were wasted and $14 \%$ underweight with the highest rates of malnutrition reported among children of mothers of no formal education and those who had primary education as their highest level of education. ${ }^{(14)}$

Nutrition education has been linked to improved child feeding and nutritional status. ${ }^{(17-20)}$ Guldan and others (2000) conducted a study in China to improve infant growth by improving infant feeding practices and after one year's intervention, the education group mothers showed significantly $(\mathrm{p}<0.05)$ higher nutrition knowledge and better reported infant feeding practices than their control group counterparts. $^{(21)}$ In Zimbabwe, counselling increased $(\mathrm{p}<0.05)$ the use of beans, fruits, green leafy vegetables, and peanut butters in porridges and sauces as complementary feeds. ${ }^{(22)}$ Roasted pumpkin seeds or beans were pounded into a powder and added to porridges for variety. ${ }^{(22)}$ A participatory nutrition education intervention in Malawi was linked to a $25 \%$ adoption rate for preparing enriched porridges and $10 \%$ for preparing soaked, pounded maize as complementary feeds and the amounts of complementary food (g/day) and intakes of, energy, and nutrients were significantly greater $(p<0.05)$ among infants $(6-23$ months $)$ in the intervention compared to those in the control group. ${ }^{(23)}$

Nutrition education has also been associated with increased complementary dietary diversity, feeding frequency, and recall of appropriate complementary foods. In Karnataka India, monthly nutrition education delivered by locally trained counsellors was linked to improved dietary diversity and feeding frequency among intervention infants (5-11 months) compared to the control infants. ${ }^{(24)}$ A study in Bangladesh using an intensive nutrition education carried out twice a month for three months revealed that, use of separate feed pots, frequency of feeding, and cooking of additional complementary feeds improved significantly in the intervention groups. ${ }^{(25)}$ A study in Brazil reported that the use of recommended complimentary foods, maternal practices and diets among Brazilian children (12-18 months) improved with nutrition counselling. ${ }^{(26)}$ A community-based responsive feeding program in Bangladesh, mothers in the intervention group gave their children more vegetables and spontaneously recalled more feeding messages at a 5-month follow-up than those in the non-intervention group. ${ }^{(27)}$

In Uganda, a project on school-based nutrition education and promotion of orange-fleshed sweet potato as a foodbased strategy for increasing Vitamin A uptake was executed to farmers in urban and peri-urban areas of Kampala Capital City Authority (KCCA) by the International Potato Center (CIP). Part of this Schools OFSP project involved providing nutrition education alongside the agricultural training to caregivers of children aged 2-6 years.

The aim of this research was to provide results on a component of the Schools OFSP project that assessed the influences of the community-level OFSP and nutrition education interventions on the knowledge, attitudes and child feeding practices of caregivers.

\section{Materials and Methods}

\subsection{Study Design}

The study was conducted among communities that benefited from the Schools OFSP project that was carried out in four divisions of Kampala Capital City Authority (KCCA); Kawempe, Rubaga, Nakawa and Makindye (excluding Kampala Central division, which is mainly business oriented) The Schools OFSP project was built on the concept of using schools as a conduit (dissemination route) for agricultural technologies and services to the community (households). Five schools were purposively selected from four Divisions. Activities for both the Schools OFSP and the nutrition education sub-component took place at the five selected schools in the divisions of Kawempe, Rubaga and Nakawa, leaving out Makindye which was the control area. The fifth division of Kampala was excluded from the project and survey because it mainly business district. The pupils, Teachers and caregivers from communities surrounding the schools who participated in the OFSP project and whose main livelihoods were significantly dependent on urban and peri-urban agriculture constituted the target group of the Schools OFSP project. The study divisions of Kampala City Council Authority (Kawempe, Rubaga, Nakawa and Makindye) and the interventions carried out are shown in table 1 below.

Table 1. Study divisions

\begin{tabular}{lcll}
\hline \multirow{2}{*}{ Division-level Interventions } & \multicolumn{2}{l}{ Orange Fleshed Sweet Potato Production } \\
\cline { 3 - 4 } & & Yes & No \\
\hline \multirow{2}{*}{ Nutrition Education } & Yes & Kawempe Division & Nakawa Division \\
& No & Rubaga Division & Makindye Division \\
\hline
\end{tabular}

Respondents for the study were selected from among these beneficiaries as representatives of households they came from. The Schools that were selected are those; whose Administration were willing to take up the project and were able to give it time on the school time table, those that had 
agriculture/farming as part of their curriculum, had agricultural land which was regularly used for cultivation and whose pupils came from the farming communities around the school.

\subsection{Materials}

The OFSP production intervention in Kawempe and Rubaga divisions of Kampala Capital City Authority (KCCA) ran from 2004-2006 and had two components: the agriculture component of the project used planting materials of two varieties of OFSP (Kakamega and Ejumula) with schools as venues for training, and the knowledge transfer component. The target group for the intervention included school children, their teachers of science and agriculture, parents/ caregivers, farmers and non-farmers in the community.

The nutrition education intervention was introduced in 2005 in Kawempe and Nakawa divisions of KCCA using a school-based model of knowledge transfer. Schools provide the venues for training and the pupils who participate would influence decisions at the household. Household with access to farming land and at least one child aged 2-6 years were selected to participate in the nutrition education. At least three Nutrition education sessions were conducted in each of the five school community per division with an inter-session period of 4-5 weeks. In Kawempe the training targeted the same five school community as the agricultural training but there was no agricultural intervention in Nakawa division. The training included vitamin A related knowledge, and preparation of complementary feeds for children (2-6 years) using clean hands, water, and utensils. A total of 996 parents and 657 school children were trained.

\subsection{Food Preparation}

Participants of nutrition education classes received hands on instruction on the preparation of maize porridge, meat and a combination dish, 'kitoobero', suitable for feeding children of weaning age and up.

Preparation of 'kitoobero', a highly nutritious complementary dish for weaning children, was also taught during the nutrition education sessions. 'Kitoobero' is a local word adopted from the central region (luganda language) and it means a mixture of different foods, kitoobero of food therefore means a meal made by combining and cooking more than two foods together. Participants were also taught how to keep food portions (that were to be eaten later) warm on low heat and to avoid food spoilage. Also participants were encouraged to steam vegetables separately from 'kitoobero' because they are not easily mashed and children tend to dislike their green/purple color. If a child refuses vegetables, then fruit juice is substituted as a source of micronutrients. The teaching of making 'kitoobero' to participants of nutrition education therefore aimed at providing the growing child with adequate nutrients to promote growth and development

A structured production/KAP questionnaire was used to evaluate the adoption of OFSP and assess the nutrition education on Vitamin A related nutrition and preparation of complementary feeds. The respondents for this study were Caregivers of young children aged 2-6 years, in the selected divisions of Kampala district who had participated in the interventions except for Makindye where there were no interventions. In order to control for breast feeding, study children were those above two years of age. One child (aged 2-6 years) from each household was used for reference in the study and was called the index child.

\subsection{Inclusion and Exclusion Criteria}

The following criterion was used to include household in the study:

Households that were practicing farming and had child caregivers who stayed in the area during the period of study. Households with children that fell in the age range of 2-6 years (preschool) and had no health complications (physical or mental).

\subsection{Ethical Issues}

Ethical approval for this research was given by the Uganda National Council for Science and Technology. In addition, written informed consent of all respondents for the study (or their legal guardians if they were minors) was obtained before involving them.

\subsection{Sample Size}

A sample of 457 households with childcare givers involved in farming and having children of 2-6 years were randomly selected from the four divisions. The sample size was determined using the following formula at $95 \%$ confidence. $^{(28)}$

Sample size, $n=\frac{\alpha_{0}\left(1-\alpha_{0}\right)+\alpha_{1}\left(1-\alpha_{1}\right)}{(m . e)^{2}}=111$ household per division

Where: $\alpha_{0}$ Prevalence proportion of VAD among children (6-59 months) in Central Uganda before the intervention, which was $22 \%$. ${ }^{(29)} \alpha_{1=}$ Projected prevalence proportion after intervention $=12 \%$, and m.e $=$ minimum error $=0.05$. Although the calculated sample size was 444 Households, a total of 457 were recruited representing a response rate of $102.9 \%$ to cater for any drop outs. In each school community about 20 households were selected from those that participated in the training except for Makindye division.

\subsection{Data Management and Analysis}

The Survey was carried out by trained Interviewers and the questionnaire was pre-tested and a preview meeting of the pre-test results was done to handle corrections and clarifications for example: the response of other (specify). After these corrections, the principal researcher and interviewers carried out the interviews of the Caregivers while filling the given responses. The Child caregivers were interviewed in English and Luganda with other languages interpreted. The data collection was conducted between July 
and October 2007.

The data were entered and cleaned using CsPro3.2 software, International Programs Center, Washington, U.S. and exported to SPSS Statistical Package Version 13, SPSS Inc, Chicago, USA for analysis. Chi-square tests were carried out to establish relationships between response variables and intervention groups with the level of significance set at $5 \%$.

\section{Results}

\subsection{Socio-Demographic Characteristics}

Kawempe and Rubaga had about $60 \%$ of the respondents below 45 years compared to over $90 \%$ for Nakawa and Makindye divisions. Over $90 \%$ of the respondents in all divisions were female except for Rubaga which had $84 \%$. With regard to education, $40 \%$ had primary education and about $38 \%$ had secondary education. Only between 10 to $17 \%$ of the respondent had a tertiary or University education as seen in table 2 .

Table 2. Respondent's social demographic characteristics $(N=457)$

\begin{tabular}{|c|c|c|c|c|}
\hline \multirow{2}{*}{ Characteristic } & \multicolumn{4}{|c|}{ \% of responses by Division* } \\
\hline & Kawempe & Rubaga & Nakawa & Makindye \\
\hline \multicolumn{5}{|l|}{ Age of respondent in years } \\
\hline $18-32$ & 31.9 & 30.8 & 46.2 & 37.6 \\
\hline $33-45$ & 31.0 & 34.2 & 45.2 & 44.4 \\
\hline $46-59$ & 28.4 & 22.5 & 2.9 & 5.1 \\
\hline $60-80$ & 8.6 & 12.5 & 2.9 & 5.1 \\
\hline \multicolumn{5}{|l|}{ Sex of respondent } \\
\hline Female & 91.4 & 84.2 & 91.3 & 96.6 \\
\hline \multicolumn{5}{|l|}{ Marital status of respondent } \\
\hline Single & 6.9 & 9.2 & 1.9 & 6.8 \\
\hline Married & 68.1 & 70.0 & 87.5 & 77.8 \\
\hline Divorced/separated & 7.8 & 7.5 & 3.8 & 6.8 \\
\hline Widowed & 17.2 & 13.3 & 6.7 & 8.6 \\
\hline \multicolumn{5}{|l|}{ Relationship to household head } \\
\hline Spouse & 57.8 & 55.8 & 77.9 & 76.1 \\
\hline Other relative & 2.6 & 4.1 & 2.9 & 3.4 \\
\hline \multicolumn{5}{|l|}{ Maximum level of formal education } \\
\hline No formal education & 1.7 & 1.7 & 8.7 & 6.8 \\
\hline Lower primary (P1-P4) & 6.0 & 11.7 & 7.7 & 7.7 \\
\hline Upper primary (P5-P7) or J1 & 40.5 & 31.7 & 34.6 & 26.5 \\
\hline Lower secondary (S1-S4) or J2 & 37.9 & 35.8 & 34.6 & 39.3 \\
\hline Upper secondary (S5-S6) & 3.4 & 1.7 & 2.9 & 2.6 \\
\hline College (Technical and National Teachers' Colleges) & 7.8 & 13.3 & 9.6 & 15.4 \\
\hline University & 2.6 & 4.2 & 1.9 & 1.7 \\
\hline \multicolumn{5}{|l|}{ Economic occupation } \\
\hline Long-term salaried employment & 13.8 & 15.0 & 15.4 & 19.7 \\
\hline Casual laborer & 6.0 & 5.0 & 5.8 & 6.0 \\
\hline Licensed business owner & 4.3 & 10.8 & 3.8 & 0.9 \\
\hline Unlicensed (petty trader) & 23.3 & 25.8 & 35.6 & 31.6 \\
\hline Urban farmer & 31.0 & 22.5 & 9.6 & 12.8 \\
\hline \multicolumn{5}{|l|}{ Length of time lived in area } \\
\hline$<12$ months & 0.9 & 1.7 & 0 & 2.6 \\
\hline $1-2$ years & 4.3 & 3.3 & 8.7 & 9.4 \\
\hline$>2 \&<5$ years & 11.2 & 12.5 & 19.2 & 12.8 \\
\hline$>5 \&<=10$ years & 18.1 & 18.3 & 32.7 & 14.5 \\
\hline$>10$ years & 65.5 & 64.2 & 39.4 & 60.7 \\
\hline
\end{tabular}

*Interventions implemented in the divisions of Kampala Capital City Authority (KCCA): Kawempe division (nutrition education + OFSP production); Rubaga division (OFSP production); Nakawa division (nutrition education); and Makindye division (control)

\subsection{Child Feeding Practices}

Table 3 shows percentage distribution on who prepares meals for the child and whether lunch and dinner for the index child were served separately. Mothers and grandmothers were the main decision makers on the food prepared for index children. There were significantly more mothers as a $\%$ of main decision makers in Nakawa (81\%) and Makindye (70\%) than Kawempe (60\%) and Rubaga $(65 \%)$, but the significance has no relevancy to the interventions. The majority of the children took their meals from that of the family. At least $20 \%$ of the respondents 
served lunch and dinner separately for the child with no significant differences between divisions. Thus any major nutritional interventions should target the Caregivers knowledge, attitudes and practices of child feeding and the first meal the child takes.

Table 4 shows results on whether the child eats from its own plate, the number of meals per day, number of snacks between meals, number of liquid drinks in a day, time the child eats meal and number of times dinner was missed in the week previous to the survey. Over $92 \%$ of the respondents in each division reported that the child ate from its own plate. There were no significant differences on the number of meals per day and number of snacks between meals.

Table 3. Person in charge of meals for the index child and mode of serving the meals $(N=457)$

\begin{tabular}{|c|c|c|c|c|c|}
\hline \multirow{2}{*}{ Characteristic } & \multicolumn{5}{|c|}{ \% of responses by Division* } \\
\hline & Kawempe & Rubaga & Nakawa & Makindye & P value \\
\hline Who Decides on foods prepared for index child & & & & & 0.007 \\
\hline Father & 0.9 & 1.7 & 6.7 & 2.6 & \\
\hline Mother & 60.3 & 65.0 & 80.8 & 70.1 & \\
\hline House maid & 0.9 & 0.8 & 0 & 0 & \\
\hline Grand mother & 31.9 & 27.5 & 10.6 & 22.2 & \\
\hline Other & 6.0 & 5.0 & 1.9 & 5.1 & \\
\hline Father & 0.9 & & 2.9 & 2.6 & \\
\hline Mother & 60.3 & 63.3 & 79.8 & 69.2 & \\
\hline House maid & 3.4 & 5.8 & 1.0 & 1.7 & \\
\hline Grand mother & 25.9 & 25.0 & 11.5 & 17.9 & \\
\hline Other & 9.5 & 5.8 & 4.8 & 8.5 & \\
\hline Is lunch served separately to child & & & & & 0.889 \\
\hline Yes & 17.2 & 15.8 & 18.3 & 19.7 & \\
\hline Is dinner served separately to child & & & & & 0.354 \\
\hline Prepared separately & 22.4 & 18.3 & 13.5 & 16.2 & \\
\hline Taken from family meal & 77.6 & 81.7 & 86.5 & 83.8 & \\
\hline
\end{tabular}

*Interventions implemented in the divisions of Kampala Capital City Authority (KCCA): Kawempe division (nutrition education + OFSP production); Rubaga division (OFSP production); Nakawa division (nutrition education); and Makindye division (control)

Table 4. Child feeding practices in the four divisions of $\mathrm{KCCA}(\mathrm{N}=457)$

\begin{tabular}{|c|c|c|c|c|c|}
\hline \multirow{2}{*}{ Characteristic } & \multicolumn{5}{|c|}{ \% of responses by Division* } \\
\hline & Kawempe & Rubaga & Nakawa & Makindye & P value \\
\hline Child eat from his/her own plate & & & & & 0.189 \\
\hline Yes & 96.6 & 94.1 & 98.1 & 92.3 & \\
\hline No & 3.4 & 5.9 & 1.9 & 7.7 & \\
\hline Number of meals in one day & & & & & 0.215 \\
\hline $1-3$ & 59.5 & 66.4 & 70.2 & 72.6 & \\
\hline $4-6$ & 40.5 & 32.8 & 27.9 & 26.5 & \\
\hline Number of snacks between meals & & & & & 0.261 \\
\hline None & 8.6 & 5.0 & 4.8 & 9.4 & \\
\hline $1-3$ & 78.4 & 74.8 & 73.1 & 69.2 & \\
\hline $4-6$ & 11.2 & 18.5 & 17.3 & 20.5 & \\
\hline $7+$ & 1.7 & 1.7 & 4.8 & 0.9 & \\
\hline Number of liquid drinks in one day & & & & & 0.449 \\
\hline None & 0.0 & 0.0 & 1.0 & 0.0 & \\
\hline $1-3$ & 68.1 & 55.5 & 66.3 & 65.0 & \\
\hline $7+$ & 3.4 & 6.7 & 4.8 & 4.3 & \\
\hline
\end{tabular}

*Interventions implemented in the divisions of Kampala Capital City Authority (KCCA): Kawempe division (nutrition education + OFSP production); Rubaga division (OFSP production); Nakawa division (nutrition education); and Makindye division (control)

\subsection{Knowledge of Preparation of Meals for Children}

Respondents were asked the following questions on their knowledge of meal preparation:

Today, there are many girls becoming mothers at a very young age and do not know enough about feeding children. Please tell me how you would advise a young mother, how to prepare nutritious porridge for a child using milk and maize flour as ingredients

Children below 1.5 years are usually unable to chew meat, and mothers fear to give it to them. How would you advise a mother to go about this?

Most children suffer from flatulence and other stomach problems when they eat beans, what advice would you give to mothers to overcome this problem. 
Except in Kawempe, where $56 \%$ of the respondents gave correct advice on the preparation of maize porridge, respondents from other divisions had less than $50 \%$ giving correct advice (table 5). On preparation of meat, $71 \%$ of the respondents in the divisions that received nutrition education gave correct advice compared to $27 \%$ in the divisions that did not receive nutrition education. On preparation of beans, significantly more respondents in Kawempe (76\%) and Rubaga (67\%) gave correct advice compared to $50 \%$ in Nakawa and $39 \%$ in Makindye. Note that $44 \%$ and $53 \%$ of the respondents in Nakawa and Makindye gave unhelpful advice.

Significantly more respondents in Kawempe and Nakawa $(72 \%)$ identified at least two correct combinations listed for preparation of kitoobero compared to $2 \%$ for Rubaga and
Makindye as showed in Figure $1(\mathrm{p}<0.05)$. Respondents were also asked whether they had heard of kitoobero and whether they had prepared it in the last 7 days, and more than $98 \%$ of the respondents in Kawempe and Nakawa had heard of kitoobero compared to $83 \%$ and $77 \%$ respectively for Nakawa and Makindye (table 6). This significant result is not therefore surprising because kitoobero, is a meal for weaning children that was taught in the nutrition education sessions. Sixty five percent $(65 \%)$ and $80 \%$ of the respondents in the divisions that received nutrition education, Kawempe and Nakawa, compared to $84 \%$ in Rubaga and Makindye had not prepared any kitoobero meal in the last 7 days before the survey. It is evident that the knowledge and adoption of kitoobero as a meal for children is dependent on nutrition education.

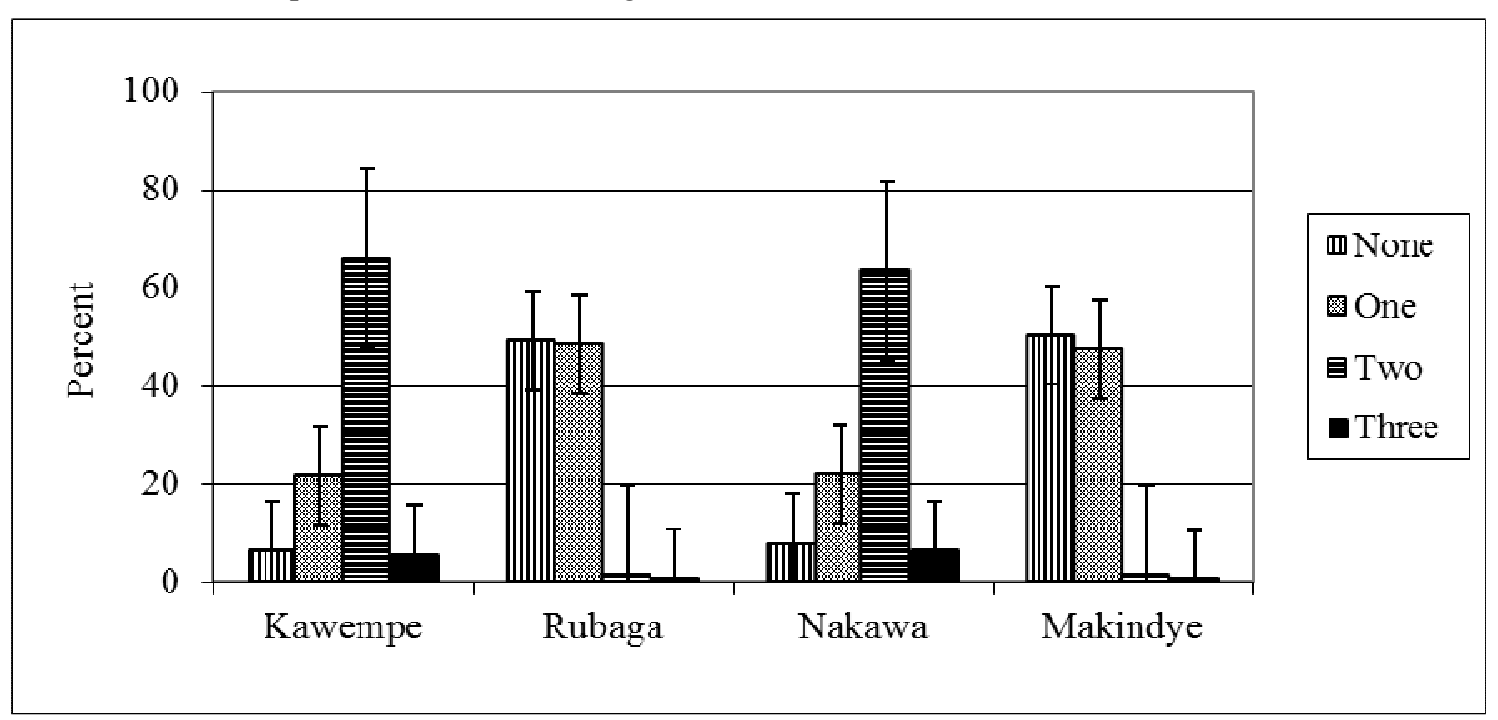

Figure 1. Respondents 'knowledge of correct kitoobero Combinations in targeted divisions of $K C C A(p<0.05)$

*Interventions implemented in the divisions of Kampala Capital City Authority (KCCA): Kawempe division (nutrition education + OFSP production); Rubaga division (OFSP production); Nakawa division (nutrition education); and Makindye division (control)

Table 5. Advice for preparation of porridge, meat and beans as weaning dishes $(N=457)$

\begin{tabular}{|c|c|c|c|c|c|}
\hline \multirow{2}{*}{ Characteristic } & \multicolumn{5}{|c|}{$\%$ of responses by Division* } \\
\hline & Kawempe & Rubaga & Nakawa & Makindye & P value \\
\hline Porridge preparation & & & & & 0.000 \\
\hline Correct advice given & 56.9 & 25.2 & 30.8 & 34.2 & \\
\hline Unhelpful advice given & 28.4 & 17.6 & 43.3 & 40.2 & \\
\hline Respondent has no advice to give & 0.9 & 0 & 0 & 0 & \\
\hline Partially correct advice given & 13.8 & 57.1 & 26.0 & 25.6 & \\
\hline Correct advice given & 71.7 & 27.7 & 71.2 & 27.4 & \\
\hline Unhelpful advice given & 25.7 & 52.9 & 26.9 & 68.4 & \\
\hline Respondent has no advice to give & 0.9 & 3.4 & 1.9 & 2.6 & \\
\hline Partially correct advice given & 1.7 & 0 & 16.0 & 1.7 & \\
\hline Bean preparation & & & & & 0.000 \\
\hline Correct advice given & 75.9 & 67.2 & 50.0 & 39.3 & \\
\hline Unhelpful advice given & 18.1 & 28.6 & 44.2 & 53.0 & \\
\hline Respondent has no advice to give & 6.0 & 1.7 & 5.8 & 6.0 & \\
\hline Partially correct advice given & 0 & 2.5 & 0 & 1.7 & \\
\hline
\end{tabular}

*Interventions implemented in the divisions of Kampala Capital City Authority (KCCA): Kawempe division (nutrition education + OFSP production); Rubaga division (OFSP production); Nakawa division (nutrition education); and Makindye division (control) 
Table 6. Knowledge and practices of kitoobero $(N=457)$

\begin{tabular}{llllll}
\hline \multirow{2}{*}{ Characteristic } & \multicolumn{4}{c}{ \% of responses by Division* } \\
\cline { 2 - 5 } & Kawempe & Rubaga & Nakawa & Makindye & P value \\
\hline Heard of kitoobero? & & & & & 0.000 \\
Yes & 99.1 & 94.1 & 82.7 & 76.9 & \\
No & 0.9 & 5.9 & 17.3 & 23.1 & 0.004 \\
Number of times made kitoobero in the last 7 days & & & & \\
None & 64.7 & 84.9 & 79.8 & 83.8 & \\
Once & 18.1 & 5.9 & 12.5 & 6.8 \\
2-3 times & 15.5 & 9.2 & 7.7 & 9.4 \\
Four meals or more & 1.7 & 0 & 0 & 0 & \\
\hline
\end{tabular}

*Interventions implemented in the divisions of Kampala Capital City Authority (KCCA): Kawempe division (nutrition education + OFSP production); Rubaga division (OFSP production); Nakawa division (nutrition education); and Makindye division (control)

\subsection{Attitude towards child nutrition}

Table 7 shows respondents attitudes on child nutrition. When respondents were asked the question: Some people believe that regular consumption of green leafy vegetables like Ddoodo (Amaranth), Nakati (Solanum spp), and fruits like ripe mangoes, has helped many children in rural areas to suffer less from measles, coughs, and diarrhoea compared to those in Kampala who do not get enough of these foods. How do you agree with this statement? About $52 \%$ of the respondents in Kawempe and Nakawa agreed strongly compared to about $13 \%$ and $12 \%$ in Rubaga and Makindye.

On attitude toward children's must to getting milk, about $70 \%$ of the respondents in Kawempe and Nakawa strongly agreed with the statement compared $20 \%$ and $15 \%$ respectively for Rubaga and Nakawa respectively.
When respondents were asked:

Maria has a child of 1 year of age. She makes sure the child eats breakfast, lunch and dinner each day and also gives her child a snack in the morning and in the afternoon. Her mother-in-law says she is spoiling the child and wasting her time - that the child just needs 2 big meals a day as it is still breastfeeding. How do you agree with Maria's mother-in-law?

About $96 \%$ of the respondents in Kawempe and Nakawa did not agree compared to $41 \%$ in Rubaga and Makindye. Over $80 \%$ of the respondents in Kawempe and Nakawa did not agree with giving a two-month old cow milk compared to $44 \%$ for Rubaga and Makindye. Kawempe and Nakawa showed more positive attitudes than Rubaga and Makindye. Evidently, right attitudes were significantly associated with Nutrition Education $(\mathrm{p}<0.05)$.

Table 7. Attitudes towards nutrition for children $(N=457)$

\begin{tabular}{|c|c|c|c|c|c|}
\hline \multirow[t]{2}{*}{ Characteristic } & \multicolumn{5}{|c|}{$\%$ of responses by Division* } \\
\hline & Kawempe & Rubaga & Nakawa & Makindye & Pvalue \\
\hline Green vegetables good for children & & & & & 0.004 \\
\hline I do not agree & 9.8 & 20.0 & 11.2 & 17.9 & \\
\hline I somewhat agree & 4.3 & 5.8 & 3.8 & 6.0 & \\
\hline I agree & 29.1 & 54.5 & 28.7 & 55.6 & \\
\hline I strongly agree & 52.4 & 13.2 & 51.6 & 12.0 & \\
\hline I do not know & 4.3 & 6.5 & 4.7 & 8.5 & \\
\hline Children must get milk & & & & & 0.003 \\
\hline I do not agree & 1.9 & 12.5 & 1.5 & 16.2 & \\
\hline I somewhat agree & 3.8 & 29.2 & 5.8 & 31.1 & \\
\hline I agree & 20.9 & 38.3 & 21.4 & 37.3 & \\
\hline I strongly agree & 73.4 & 19.2 & 71.3 & 14.7 & \\
\hline I do not know & 0 & 0.8 & 0 & 0.7 & \\
\hline Child needs 2 meals per day & & & & & 0.003 \\
\hline I do not agree & 96.2 & 41.7 & 95.8 & 40.8 & \\
\hline I somewhat agree & 2.3 & 2.1 & 2.1 & 1.2 & \\
\hline I agree & 0.6 & 53.3 & 0.8 & 52.0 & \\
\hline I strongly agree & 0.3 & 1.2 & 0.5 & 2.4 & \\
\hline I do not know & 0.6 & 1.7 & 0.8 & 2.6 & \\
\hline Two month old has cow milk & & & & & 0.003 \\
\hline I do not agree & 86.2 & 43.8 & 82.3 & 44.7 & \\
\hline I somewhat agree & 4.1 & 6.8 & 5.4 & 7.7 & \\
\hline I agree & 5.1 & 45.2 & 6.6 & 45.0 & \\
\hline I strongly agree & 4.0 & 1.7 & 4.8 & 0 & \\
\hline I do not know & 0.6 & 2.5 & 0.9 & 2.6 & \\
\hline
\end{tabular}

*Interventions implemented in the divisions of Kampala Capital City Authority (KCCA): Kawempe division (nutrition education + OFSP production); Rubaga division (OFSP production); Nakawa division (nutrition education); and Makindye division (control) 


\section{Discussion}

Majority of the Child caregivers were females and had attained at least primary level education, which may have helped in the acquisition of knowledge, positive attitudes and practices related to child feeding.

Like maize porridge and beans, meat is commonly prepared as a complimentary food in Uganda. However, a significant percentage of the caregivers do not have the required knowledge. Except for preparation of meat the significant differences for other preparations cannot be attributed to nutrition education. Maize porridge is a common food given to children in Uganda. The study shows that majority of the caregivers did not have the right knowledge of preparing porridge as a nutritious meal for children, even after being trained. This is possibly because the Nutrition education training was not long term and did not have adequate monitoring to ensure that knowledge learnt was being practice or to identify reasons why not.

Good knowledge of the right feeding practices of children and how the caretakers can ensure good child health are very important. Results of the study show that through nutrition education, respondents adopted the good practice of children having an early evening meal regularly. Respondents showed good knowledge of preparation of complementary foods and significantly more respondents who gave unhelpful advice were those that did not receive nutrition education. Respondents who received nutrition education had more positive attitudes on related child care practices. Consistent with findings from other studies, the findings show that nutrition education to caregivers enhances their knowledge, attitudes, and practices of child feeding. ${ }^{(21,22,23,24,25,26,27)}$

\section{Conclusion}

The results of this study show that divisions with nutrition education had respondents with more knowledge, positive attitudes, and practices on child feeding. Nutrition education in child feeding knowledge and practices aimed at having good child health should be taken up by the public health sector so as to boost the fight against malnutrition.

\section{Authors' Contributions}

J. Nabugoomu was a Master of Science student and Research Assistant on the Schools OFSP project of the International Potato Center (CIP). J. Nabugoomu, A. Namutebi, A. N. Kaaya, and G. Nasinyama were responsible for supervision of fieldwork and the acquisition of data for this particular study. Data analysis and interpretation was performed by J. Nabugoomu; the manuscript was drafted by Josephine Nabugoomu; the manuscript was revised critically for substantial intellectual content by J. Nabugoomu, A. Namutebi, A. N. Kaaya, and G. Nasinyama.

\section{Acknowledgements}

The authors acknowledge with gratefulness financial support for this study from Urban Harvest and the International Potato Center (CIP). The Author affiliation institute, Makerere University is acknowledged and appreciated. The interviewers, participating schools, and study participants are also acknowledged and appreciated.

\section{References}

[1] WHO. Guiding principles for complementary feeding of the breastfed child. 2003. http://whqlibdoc.who.int/paho/2003/a85622.pdf?ua=1

[2] Ruel MT, Menon P. Child feeding practices are associated with child nutritional status in Latin America: innovative uses of the demographic and health surveys. J Nutr. 2002; 132(6):1180-1187.

[3] Black MM, Dubowitz H, Hutcheson J, Berenson-Howard J, Starr RH Jr. A Randomized clinical trial of home intervention for children with failure to thrive. Pediatrics. 1995; 95:807814 .

[4] Agarwal DK, Awasthy A, Upadhyay SK, Singh P, Kumar J, Agarwal KN. Growth, behavior, development and intelligence in rural children between 1-3 years of life. Indian Pediatr. 1992; 29:467-480.

[5] UNICEF/UNU/WHO/MI Technical Workshop. Preventing iron deficiency in women and children: technical consensus on key issues. Boston, MA: International Nutrition Foundation, 1999.

[6] Bhandari N, Mazumder S, Bahl R, Martines J, Black RE, Bhan MK, Infant Feeding Study Group. An educational intervention to promote appropriate complementary feeding practices and physical growth in infants and young children in rural Haryana, India. J Nutr. 2004; 134(9):2342-2348.

[7] Lutter CK, Daelmans BM, de Onis M, Kothari MT, Ruel MT, Arimond M, Deitchler M, Dewey KG, Blössner M, Borghi E. Undernutrition, poor feeding practices, and low coverage of key nutrition interventions. Pediatrics. 2011; 128(6):e1418-27.

[8] Dewey KG, Cohen RJ, Brown KH, Rivera LL. Age of introduction of complementary food and growth of term, low birth weight breastfed infants: a randomized intervention study in Honduras. Am J Clin Nutr. 1999; 69:679-686.

[9] Kulwa KBM, Verstraeten R, Bouckaert K, Mamiro P, Kolsteren P, Lachat C. Effectiveness of a nutrition education package in improving feeding practices, dietary adequacy and growth of infants and young children in rural Tanzania: rationale, design and methods of a cluster randomised trial. BMC Public Health 2014; 14:1077.

[10] Latham MS, Kinoti LS. Improvements in Growth following Iron Supplementation in Young Kenyan School Children. Nutrition. 1990; 6:159-165.

[11] Penny ME, Creed-Kanashiro HM, Robert RC, Narro MR, Caulfield LE, Black RE. Effectiveness of an educational intervention delivered through the health services to improve nutrition in young children: a cluster-randomised controlled trial. Lancet. 2005; 365(9474):1863-1872. 
[12] Kuriyan R, Kurpad AV. Complementary feeding patterns in India. Nutr Metab Cardiovasc Dis. 2012; 22(10):799-805.

[13] Lawan UM, Amole GT, Jahum MG, Sani A. Age-appropriate feeding practices and nutritional status of infants attending child welfare clinic at a Teaching Hospital in Nigeria. J Family Community Med. 2014; 21(1):6-12.

[14] Uganda Bureau of Statistics (UBOS) and Macro International Inc. 2012. Uganda Demographic and Health Survey 2011. Pages 9.

[15] Wamani H, Astrøm AN, Peterson S, Tylleskär T, Tumwine JK. Infant and young child feeding in western Uganda: knowledge, practices and socio-economic correlates. J Trop Pediatr. 2005; 51(6):356-361.

[16] Kulwa KB, Kinabo JL, Modest B. Constraints on good childcare practices and nutritional status in urban Dar-es-Salaam, Tanzania. Food Nutr Bull. 2006; 27(3):236-244.

[17] Webb P, Block S. Nutrition knowledge and parental schooling as inputs to child nutrition in the long and short run. Nutrition Working Paper No. 3. BAPPENAS/DEPARTMEN PERTANIAN/USAID/DAI FOOD POLICY ADVISORY TEAM. 2003. http://pdf.usaid.gov/pdf_docs/Pnade922.pdf.

[18] Salehi M, Kimiagar SM, Shahbazi M, Mehrabi Y, Kolahi AA. Assessing the impact of nutrition education on growth indices of Iranian nomadic children: an application of a modified beliefs, attitudes, subjective-norms and enabling-factors model. Br J Nutr. 2004; 91(5):779-787.

[19] Bezner Kerr R, Berti PR, Shumba L. Effects of a participatory agriculture and nutrition education project on child growth in northern Malawi. Public Health Nutr. 2011; 14(8):1466-1472.

[20] Shi L, Zhang J. Recent evidence of the effectiveness of educational interventions for improving complementary feeding practices in developing countries. J Trop Pediatr. 2011; 57(2):91-98.

[21] Guldan GS, Fan HC, Ma X, Ni ZZ, Xiang X, Tang MZ. Culturally Appropriate Nutrition Education Improves Infant
Feeding and Growth in Rural Sichuan, China. J Nutr. 2000;130(5):1204-1211.

[22] Paul KH, Muti M, Chasekwa B, Mbuya MN, Madzima RC, Humphrey JH, Stoltzfus RJ. Complementary feeding messages that target cultural barriers enhance both the use of lipid-based nutrient supplements and underlying feeding practices to improve infant diets in rural Zimbabwe. Matern Child Nutr. 2012; 8(2):225-238.

[23] Hotz C, Gibson RS. Participatory nutrition education and adoption of new feeding practices are associated with improved adequacy of complementary diets among rural Malawian children: a pilot study. Eur J Clin Nutr. 2005; 59(2):226-237.

[24] Kilaru A, Griffiths PL, Ganapathy S, Ghosh S. Communitybased nutrition education for improving infant growth in rural Karnataka. Indian Pediatr. 2005; 42(5):425-432.

[25] Roy SK, Fuchs GJ, Mahmud Z, Ara G, Islam S, Shafique S, Akter SS, Chakraborty B. Intensive nutrition education with or without supplementary feeding improves the nutritional status of moderately-malnourished children in Bangladesh. J Health Popul Nutr. 2005; 23(4):320-330.

[26] Santos I, Victora CG, Martines J, Gonçalves H, Gigante DP, Valle NJ, Pelto G. Nutrition counseling increases weight gain among Brazilian children. J Nutr. 2001; 131(11):2866-2873.

[27] Aboud FE, Moore AC, Akhter S. Effectiveness of a community-based responsive feeding programme in rural Bangladesh: a cluster randomized field trial. Matern Child Nutr. 2008; 4(4):275-286.

[28] Kirkwood RB. 1988. Essential Medical Statistics. 2nd ed. Blackwell Scientific Publications. Oxford, London Edinburgh. $197 \mathrm{p}$.

[29] Uganda Bureau of Statistics (UBOS) and Macro International Inc. 2007. Vitamin Addendum to Uganda Demographic and Health Survey 2006. 